\title{
Giant thymoma successfully resected via hemiclamshell thoracotomy: a case report
}

\author{
Weigang Zhao, Wentao Fang \\ Department of Thoracic Surgery, Shanghai Chest Hospital, Shanghai Jiao Tong University, Shanghai 200030, China \\ Correspondence to: Wentao Fang. Department of Thoracic Surgery, Shanghai Chest Hospital, Shanghai Jiao Tong University, Shanghai 200030, \\ China. Email: vwtfang@hotmail.com.
}

\begin{abstract}
Thymoma is an epithelial neoplasm of the thymus. It commonly lies in the anterior mediastinum and represents $20-30 \%$ of mediastinal tumours in adults. In this report we present a case of giant thymoma locating in the anterior-inferior mediastinum. A 46-year-old male came to our institute with slight pectoralgia and dyspnea. Chest CT shows a giant tumor measuring $19 \mathrm{~cm} \times 16 \mathrm{~cm} \times 15 \mathrm{~cm}$ in the left thoracic cavity. After careful examination, we performed surgery. At surgery, we found the tumor was adherent to left upper lobe of the lung, mediastinal pleura, and parietal pleural. The tumor was completely resected with combined resection of part left upper lobe of lung. The weight of the tumor was 2,135 g. Pathological diagnosis indicated a type $\mathrm{AB}$ thymoma according to the World Health Organization classification and a diagnosis of Masaoka stage IIB was made.
\end{abstract}

Keywords: Giant thymoma; ectopic thymoma; hemiclamshell

Submitted Jan 27, 2016. Accepted for publication May 12, 2016.

doi: $10.21037 /$ jtd.2016.06.41

View this article at: http://dx.doi.org/10.21037/jtd.2016.06.41

\section{Introduction}

Thymomas usually locate in the anterior-superior mediastinum and account for $20-30 \%$ of mediastinal tumours in adults $(1,2)$. Median sternotomy is the standard approach for normal size thymoma. Different studies showed different approaches toward giant thymoma. However, there is still no consensus on the incision of giant thymoma. We herein present a case of giant thymoma that was surgically resected through hemiclamshell thoracotomy. The resected specimen was a World Health Organization (WHO) type AB thymoma, Masaoka stage IIB.

\section{Case presentation}

A 46-year-old man with slight pectoralgia and dyspnea was referred to our hospital, chest X-ray showing an abnormal shadow in the left thoracic cavity (Figure 1). The CT images (Figure 2) show that the tumor was about $19 \mathrm{~cm} \times 16 \mathrm{~cm}$ $\times 15 \mathrm{~cm}$ in the left thoracic cavity. The tumor had some adhesion to the left lung, mediastinal pleura, and parietal pleural. The tumor is so huge that it pushed the heart and mediastinum to the right side. Surgical access to the mass was first chose as left anterolateral thoracotomy through the $4^{\text {th }}$ intercostals space in the semi-lateral decubitus position, which was extended to hemiclamshell approach since the upper pole of tumor was difficult to expose. At surgery, the tumor was found to be closely adherent to the upper lobe of the left lung, slightly adherent to the mediastinal pleura and parietal pleura. The feeding vessels of the tumor were branching from internal thoracic vessels and collateral blood vessels were extensive surrounding the giant tumor. The tumor was completely resected with combined resection part of the upper lobe of the left lung. The excised specimen shows a tumor measuring $19 \mathrm{~cm} \times 16 \mathrm{~cm} \times 15 \mathrm{~cm}$ and the weight of the tumor was $2,135 \mathrm{~g}$ (Figure 3). Microscopic examination shows part of the tumor was spindle shaped, arranged as fasciculation, some district of the tumor with a lymphocyte rich component and oval cells were detected in it (Figure 4), tumor cells were seen in the capsular of tumor. The resected left lobe of lung is free from tumor. These 


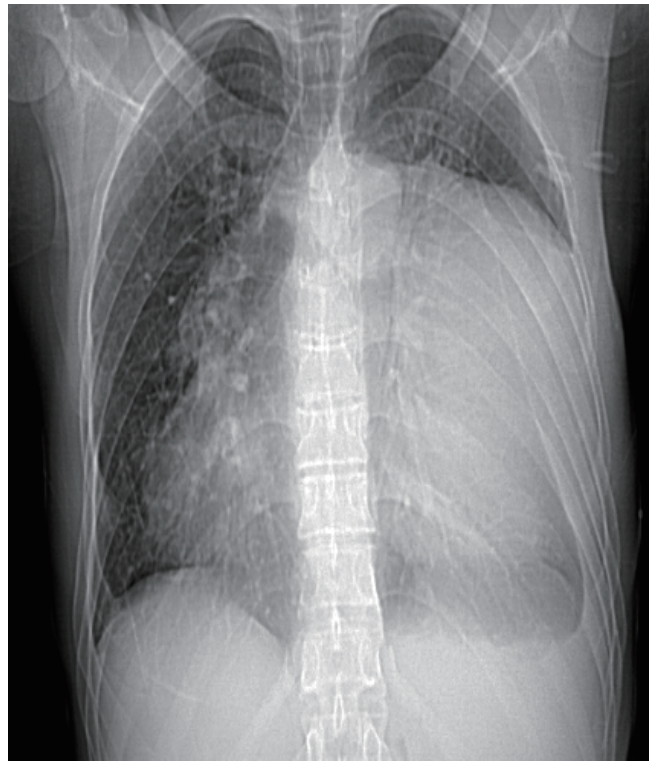

Figure 1 Chest $\mathrm{X}$-ray shows a giant mass in the left chest.

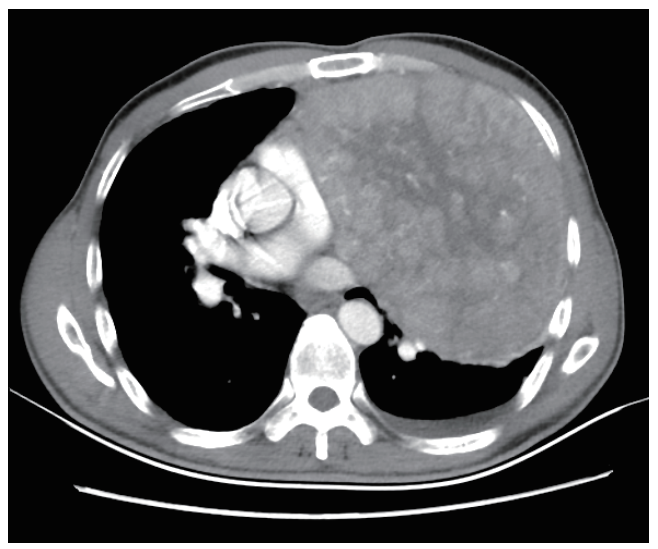

Figure 2 Chest CT shows a mass measuring $19 \mathrm{~cm} \times 15 \mathrm{~cm}$ in diameter, in contact with the left lung, mediastinal pleura, and parietal pleural.

histopathologic findings show that the tumor was a type $\mathrm{AB}$ thymoma according to the World Health Organization classification and Masaoka stage IIB.

\section{Discussion}

Thymomas are rare neoplasias with an incidence of 0.15 cases per 100,000 people each year. They represent $20-30 \%$ of mediastinal tumours in adults $(1,2)$. Most thymomas are asymptomatic, but patients can feel the symptoms such as chest pain and dyspnea due to the

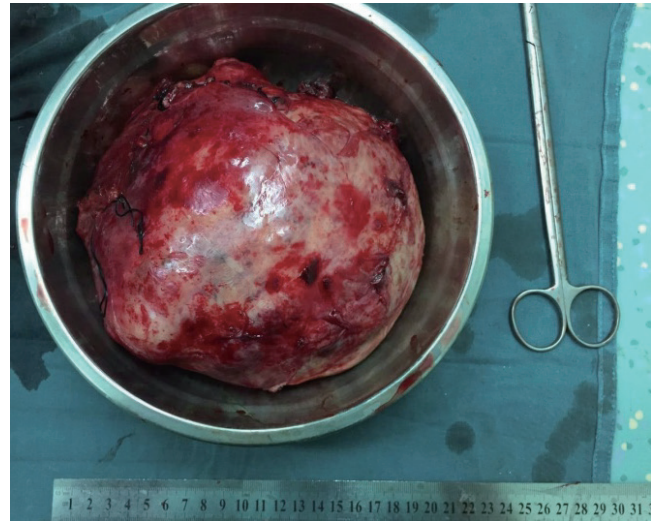

Figure 3 Gross pathologic finding of the tumor: an encapsulated mass measuring $19 \mathrm{~cm} \times 16 \mathrm{~cm} \times 15 \mathrm{~cm}$, the scissors as a contrast.

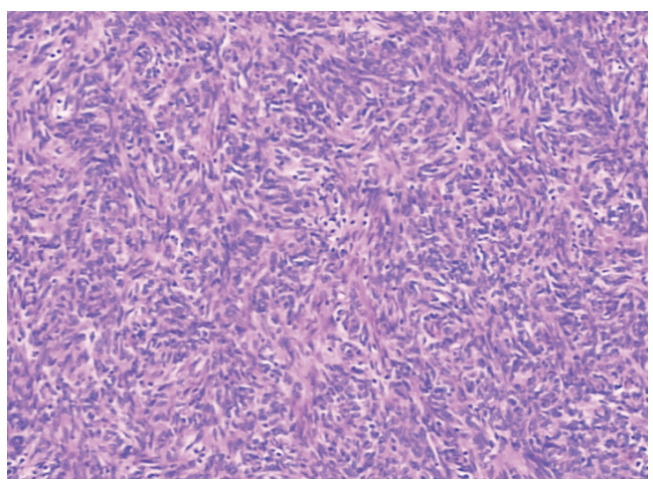

Figure 4 Pathological findings (hematoxylin/eosin staining) from the postoperative specimens $(\times 100)$.

compression of the surrounding organs with the rapid growth of the tumor. Superior vena cava syndrome can be seen in patient with giant thymoma due to tumor invasion of the surrounding tissues (3). Myasthenia gravis, pure red cell aplasia, hypogammaglobulinemia are also seen in some patients with thymoma (4). In this case, the patient had symptoms such as pectoralgia and dyspnea due to the compression of the surrounding organs. Although this patient combined with cirrhosis, the surgery was performed as quickly as possible since the patient had these symptoms.

In this case, the tumor was located in the anterior-inferior mediastinum and protruded into pleural cavity. It needs to be distinguished with solitary fibrous tumors, tumors of pleural origin, chest wall tumors, and metastatic tumors. It is not easy to identify giant thymoma with solitary fibrous tumors due to the similar image features. The only way 
to definitive diagnosis is pathological diagnosis. However, definitive diagnosis is difficult to obtain before surgery is performed. Biopsy or fine-needle aspiration (FNA) is limited for giant thymoma due to some drawbacks of them. First of all, we can't achieve a firm diagnosis by biopsy or FNA since we can only acquire a very small tissue of the tumor, benign histopathology obtain by FNA or biopsy does not exclude the chance of malign tumor. Secondly, there is potential risk of tumor cell dissemination and bleeding by FNA or biopsy. Filosso et al. suggested that transthoracic CT-guided tru-cut biopsy was preferred over FNA since the first procedure can provide more pathological tissue for correct diagnosis, they nevertheless failed to obtain a conclusive diagnosis (5). So it seems that postoperative pathological diagnosis is the only way to definitive diagnosis and giant thymoma should be suspected whenever a large intrathoracic mass is observed. Endo et al. reported a significant relation between the histological subtype of thymic epithelial tumors and FDG-PET accumulation (6). Terzi et al. confirmed $\mathrm{SUV}_{\text {max }}$ had strong relation with the Masoka stages (7).

Although median sternotomy is the standard approach for thymomas, only few cases of giant thymomas were resected via median sternotomy (8). Usually Median sternotomy was performed when tumor with normal size had invaded into the innominate vein (9), but was not suitable to the giant thymoma due to the bad access to the hilum or posterior thorax. Giant thymomas were resected through anterolateral thoracotomy in three studies (10-12). Hemiclamshell approach is a practical approach for giant thymomas due to better access to upper thoracic cavity compared with anterolateral thoracotomy. However, some people still choose anterolateral thoracotomy as the first choice to giant thymoma since the incision of this approach can be extended to either a posterolateral approach or a hemiclamshell approach (12). In our case, we also took anterolateral thoracotomy as first choice and extended the incision to hemiclamshell approach when the upper pole of tumor was difficult to expose. Although two cases of giant thymomas were resected via a posterolateral approach $(5,13)$, the deficiency of bad access to anterior mediastinum limited its further application.

In conclusion, both hemiclamshell approach and anterolateral thoracotomy are reasonable approaches for giant thymomas. Anterolateral approach is suggested as first choice for giant thymoma since it is less invasive and more adaptable compared with hemiclamshell approach. The incision should be extended to hemiclamshell approach when the upper pole of tumor was difficult to expose.

\section{Acknowledgements}

None.

\section{Footnote}

Conflicts of Interest: The authors have no conflicts of interest to declare.

Informed Consent: Written informed consent was obtained from the patient for publication of this manuscript and any accompanying images.

\section{References}

1. Tomaszek S, Wigle DA, Keshavjee S, et al. Thymomas: review of current clinical practice. Ann Thorac Surg 2009;87:1973-80.

2. Joven MH, Palalay MP, Sonido CY. Case report and literature review on Good's syndrome, a form of acquired immunodeficiency associated with thymomas. Hawaii J Med Public Health 2013;72:56-62.

3. Kim HJ, Cho SY, Cho WH, et al. An unusual case of superior vena cava syndrome caused by the intravascular invasion of an invasive thymoma. Tuberc Respir Dis (Seoul) 2013;75:210-3.

4. Briones J, Iruretagoyena $\mathrm{M}$, Galindo $\mathrm{H}$, et al. Thymoma associated with hypogammaglobulinaemia and pure red cell aplasia. Ecancermedicalscience 2013;7:364.

5. Filosso PL, Delsedime L, Cristofori RC, et al. Ectopic pleural thymoma mimicking a giant solitary fibrous tumour of the pleura. Interact Cardiovasc Thorac Surg 2012;15:930-2.

6. Endo M, Nakagawa K, Ohde Y, et al. Utility of 18FDGPET for differentiating the grade of malignancy in thymic epithelial tumors. Lung Cancer 2008;61:350-5.

7. Terzi A, Bertolaccini L, Rizzardi G, et al. Usefulness of 18-F FDG PET/CT in the pre-treatment evaluation of thymic epithelial neoplasms. Lung Cancer 2011;74:239-43.

8. Sim EK, Lee CN, Mestres CA, et al. Ectopic thymoma: a case for median sternotomy for complete thymectomy. Singapore Med J 1992;33:407-8.

9. Fazlıogulları O, Atalan N, Gürer O, et al. Cardiac tamponade from a giant thymoma: case report. J Cardiothorac Surg 2012;7:14.

10. Limmer S, Merz H, Kujath P. Giant thymoma in the anterior-inferior mediastinum. Interact Cardiovasc Thorac Surg 2010;10:451-3. 
11. Yamazaki K, Yoshino I, Oba T, et al. Ectopic pleural thymoma presenting as a giant mass in the thoracic cavity. Ann Thorac Surg 2007;83:315-7.

12. Saito T, Makino T, Hata Y, et al. Giant thymoma successfully resected via anterolateral thoracotomy: a case report. J Cardiothorac Surg 2015;10:110.

13. Gotte JM, Bilfinger TV. Resection of giant right-sided thymoma using a lateral thoracotomy approach followed by median sternotomy for completion thymectomy. Thorac Cardiovasc Surg 2007;55:336-8.
Cite this article as: Zhao W, Fang W. Giant thymoma successfully resected via hemiclamshell thoracotomy: a case report. J Thorac Dis 2016;8(8):E677-E680. doi: 10.21037/ jtd.2016.06.41 